\title{
Crowd Dynamics, Management and Control at Tourist Attractions during Special Events: A Case Study at Souq Waqif Using Pedestride ${ }^{\circledR}$ Crowd Simulation Tool
}

\author{
Ali Abdelaal \\ ali.abdelaal@qu.edu.qa \\ Qatar Transportation and Traffic Safety Center, Qatar University, Doha, Qatar \\ Charitha Dias \\ cdias@qu.edu.qa \\ Qatar Transportation and Traffic Safety Center, Qatar University, Doha, Qatar \\ Majid Sarvi \\ majid.sarvi@unimelb.edu.au
}

The Department of Infrastructure Engineering, The University of Melbourne, Melbourne, Australia

\author{
Wael Alhajyaseen \\ wyaseen@qu.edu.qa \\ Qatar Transportation and Traffic Safety Center, Qatar University, Doha, Qatar \\ Faris Tarlochan \\ faris.tarlochan@qu.edu.qa \\ Qatar Transportation and Traffic Safety Center, Qatar University, Doha, Qatar
}

\begin{abstract}
Large crowds can be expected at famous tourist attractions, e.g., Souq Waqif, during special events such as the FIFA World Cup 2022. A comprehensive understanding of crowd dynamics is extremely important in order to ensure safety of crowds and efficiency of crowd flows at large gathering spots. Pedestrian crowd simulation tools can be used to evaluate crowd flows and to verify crowd management and control strategies at public infrastructure. The objective of this study is to evaluate safety and efficiency of crowd flows at Souq Waqif, both under normal and emergency situations using Pedestride ${ }^{\circledR}$ Crowd Simulation tool developed at Melbourne University. This simulation model has been calibrated and validated using empirical data collected through controlled experiments and real-world observations. By simulating the increased visitor demand at Souq Waqif as a case study, we aim to highlight any required design modifications and to recommend and verify crowd management strategies in order to mitigate any unfavorable situations, such as stampede during any emergency. The study shows that at increased demands and during emergency evacuation, crowds tend to take similar route. Further, increased demands could elevate the maximum crowd density up to $6 \mathrm{p} / \mathrm{m} 2$ at gates and junctions. In order to mitigate such unfavorable situations, dynamic exit signs are needed to direct flows to other clear exits to avoid herding effect.
\end{abstract}

Keywords: Crowd dynamics; Crowd simulation; Crowd safety; Emergency evacuation; Mega-events

\section{INTRODUCTION}

Souq Waqif is one of the main tourist destinations in Qatar due to its history, architecture, authenticity, and proximity to other touristic places such as the Museum of Islamic Arts and Cornish. It is also a destination for buying spices, traditional garments, gifts and souvenirs. Literal translation of 'Souq Waqif' is the 'standing market'. It was founded at least 100 years ago and served as a gathering place for locals, Bedouin (nomads) traders, and fishermen. Souq Waqif is located near Msheireb district in Qatar 
as shown in Figure. 1. It covers an area of $164,000 \mathrm{~m} 2$ at the city waterfront (Furlan and Faggion, 2015). The buildings inside the Souq are constructed from basic materials such as wood, bamboo, straw, and clay with no additional painting as they maintain the natural colour of stones and original building material. The Souq layout makes it appear as a maze with multiple entrances and exits, and relatively complex and irregular network of paths or passages, some of them are open-air. The Main Street and a corridor inside Souq are shown in Figure. 2. Between 2006 and 2008, the Souq went through a major restoration and reconstruction work aiming to preserve the architectural identity of the place that might have transformed due to the rapid development of the city. Moreover, the new Souq includes several additional features such as new art galleries, and a number of restaurants and cafes.

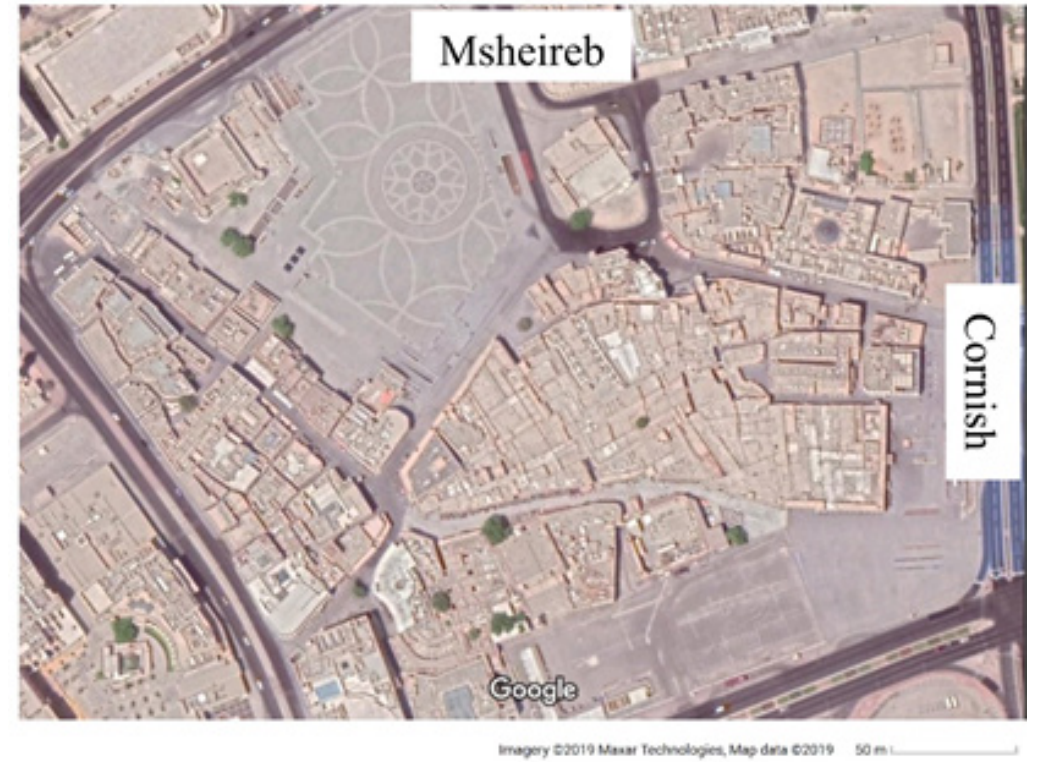

Figure 1: Map of Souq Waqif and surrounding area (Google).

Such a famous destination is likely to be visited by tourists who aim to know about the history of Qatar, try some traditional food, and shop for souvenirs. This type of crowd has distinct characteristics. They might not know the site map, they might not have a specific plan for touring the place, and they will roam the place with the aim of exploration and recreation. Even for some residents, navigating through the very similar corridors of Souq Waqif is a challenge.

Visitors to Souq reported a difficulty in reaching their desired destination due to the limited number of signs. It was also reported that there are no clear indicators of main entrances (Nafi et al., 2015), resulting in a significant need of additional signage at the Souq (Furlan and Faggion, 2015). Another study found that entrances were well defined; however, navigating within the Souq and the very similar looking corridors can be misleading and time consuming when needing to exit quickly (Tannous and Furlan, 2018).

In order to ensure tourists' satisfaction, to enhance the efficiency of visitors' circulation 
inside the Souq, and to avoid any unfavourable situations, e.g., stampede during high visitor demand or emergency situations, the crowd flows needs to be managed and guided properly. While some studies have explored the interaction of visitors and traders, and how this impacts time spent inside the market, or increases the density of the crowds in certain locations (Kusuma, 2017; Kusuma et al., 2016a, 2016b), this study aims at analysing the overall behaviour of the crowd during normal and emergency evacuation modes, using a microscopic pedestrian crowd simulation tool.

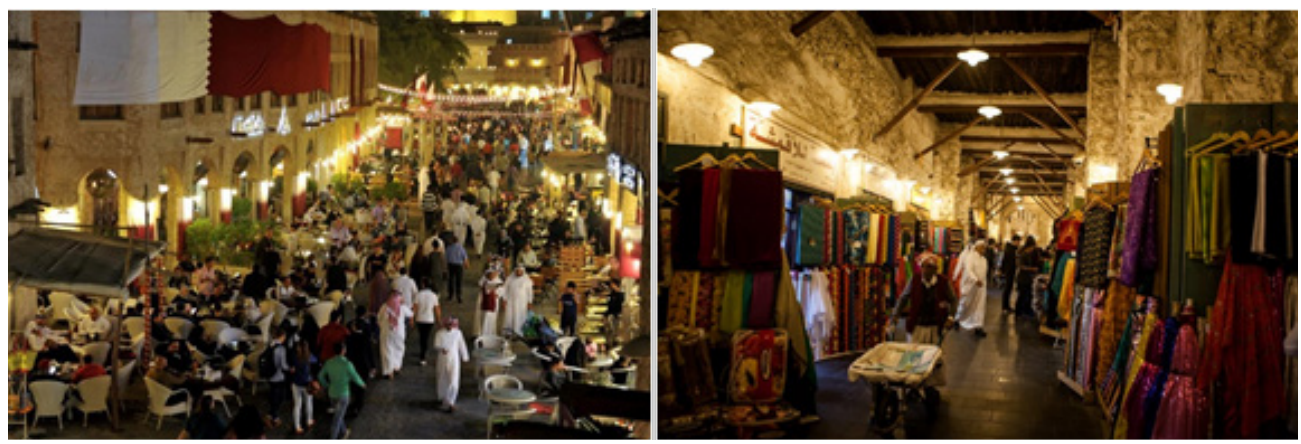

Figure 2: Main street in Souq Waqif(left, source: The Peninsula, local news agency), and an example of corridors in the Souq (right) (El-Hamalawy, 2015).

\section{METHODOLOGY}

Pedestride ${ }^{\circledR}$ software (https://www.pedestride.com/) is used in this study to understand Souq visitors' behaviour during an evacuation process. The software utilizes a number of models such as the social force model introduced by Helbing, Farkas and Vicsek (Helbing et al., 2000). The simulation model works at the "operational level" (Haghani and Sarvi, 2018) or the "walking behavior" (Antonini et al., 2006) level, based on the social force model. This model is connected to further superior modelling levels of pathfinding and directional choice, also known as, the "tactical level" (Asano et al., 2010; Bode and Codling, 2013; Haghani et al., 2015, 2018; Haghani and Sarvi, 2016) in addition to a modelling layer for directional choice change. Moreover, the reaction time (also known as, the "strategic level" (Augustijn-Beckers et al., 2010; Lovreglio et al., 2015). The below equation is a simplified version of the model utilized by Pedestride ${ }^{\circledR}$ software;

$$
\vec{f}_{l}=\vec{f}_{\text {des }, i}+\vec{f}_{i j(i \neq j)}+\vec{f}_{\text {wall }, i}+\varphi\left[\vec{f}_{\text {push }}+\vec{f}_{\text {friction }}\right]+\vec{\varepsilon}
$$

Where, $\vec{f}_{\text {des }, i}$ is the desired force, $\vec{f}_{i j(i \neq j)}$ is the social interaction force, and $\vec{f}_{\text {wall }, i}$ is the force exerted by walls. When the crowd density reaches a higher limit that pedestrians have physical contacts pushing and friction forces are also activated, i.e., $\varphi \neq 0$. Finally, $\vec{\varepsilon}$ represents fluctuation due to randomness.

Map of Souq Waqif was adopted from simplified building geometrical reconstruction (Tannous and Furlan, 2018) and satellite images as shown in Figure. 3. Two areas of the Souq were simulated in this study. In the first case study, 500 agents were distributed over an area of $2260 \mathrm{~m}^{2}$ resulting in an equivalent pedestrian density of $0.22 \mathrm{p} / \mathrm{m}^{2}$. The density was almost doubled $\left(0.45 \mathrm{p} / \mathrm{m}^{2}\right)$ in the second case study by reducing the simulated area 
to $1109 \mathrm{~m}^{2}$ as shown. The other option to increase the density was doubling the number of agents; however, this was not possible due to the software limitation. Corridor width in both case studies ranged approximately from 2.5 to $6 \mathrm{~m}$. It is worth mentioning that at the initiation of the simulation, crowd density in some corridors ranged from $2-5 \mathrm{p} / \mathrm{m}^{2}$ to simulate peak demand during mega events. This study also investigates the possibility of having certain exits blocked due to an emergency, and how this would affect the evacuation process during higher density.

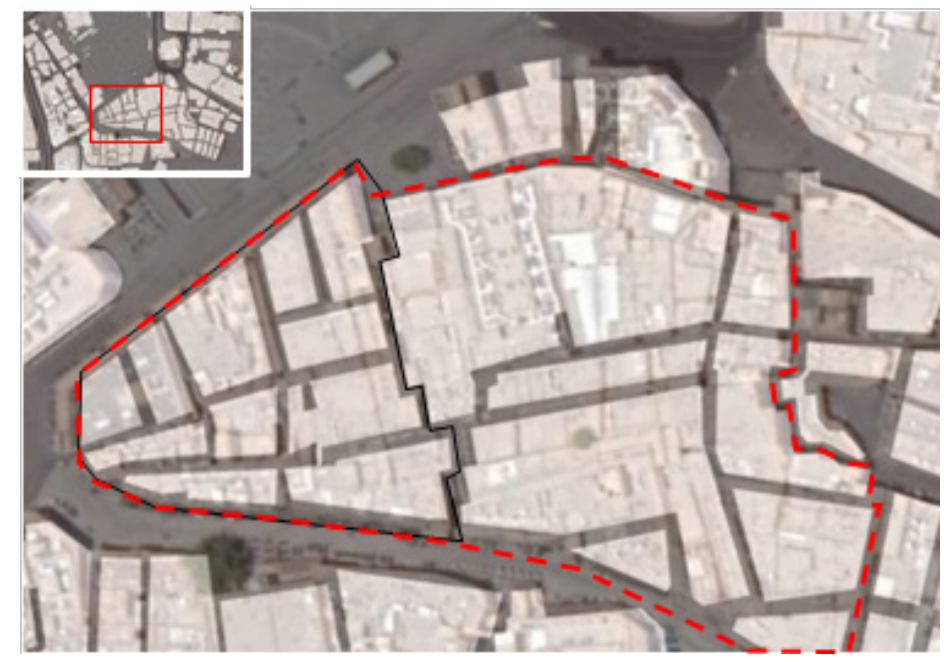

Figure 3: Area simulated ( $1^{\text {st }}$ case study area ----, $2^{\text {nd }}$ case study area --- $)$.

\section{RESULTS AND DISCUSSION}

In general, the design of egress routes in buildings or mega events is based on a number of references that can be categorized into legal regulations, handbooks, and computer simulations. The legal regulations utilize a set of static rules and prescriptive methods. For instance, the number of individuals per room and length of escape route determine the minimum width of doors. This method lacks the dynamics of an evacuation process. On the other hand, handbooks use macroscopic models during evacuation with relevance to time and space. This method can predict the time and location of congestions; however, it treats pedestrians as a body of quasi-constant size and density what gives only a coarse description of the flow. On the contrary, microscopic models simulate individual movement of each pedestrian in order to determine the crowd dynamics on an individual scale, which is used in this analysis.

Multiple reasons could trigger an evacuation, but the most common type is forced evacuation from an enclosed space as a result of a threat like fire or smoke. The simulation assists designers in evaluating their evacuation plans in terms of time needed to completely evacuate a given space, location and number of exits, and possibility of having stampedes. In this study, we considered the evacuation time as the time needed to evacuate $98 \%$ of the crowd. The results showed that evacuation time was higher for higher density crowd. The average evacuation time for normal and emergency evacuation in the first case was 55 and 63 seconds, respectively. On the other hand, the second case 
study resulted in an average evacuation time of 62 and 77 seconds for the normal and emergency evacuation scenarios, respectively. Despite having multiple routes to exit the Souq, crowds were observed to always take the same exit leading to a peak demand at certain gates, mainly due to herding effect which is a common phenomenon under panic situation. It should be noted that in the exit choice model used in Pedestride we used the default parameters.

Comparing normal and emergency evacuation showed no difference in the rates of evacuation for the first case study as illustrated in Figure. 4. However, when the crowd density was increased in the second case study, a change in the trend between normal and emergency evacuation was observed. Figure. 5 shows that there is almost no difference in percentage of agents evacuated in normal and emergency scenarios up until $20 \%$, then the difference starts to increase and less agents are evacuated for the same evacuation period which indicated a reduced crowd dynamics and possibility of stampeding.

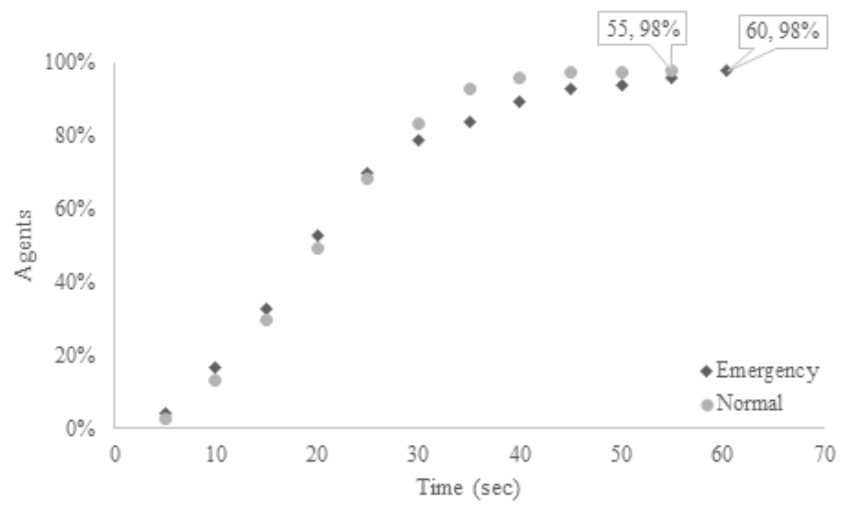

Figure 4: Percentage evacuated over time $(0.22 \mathrm{p} / \mathrm{m} 2)$

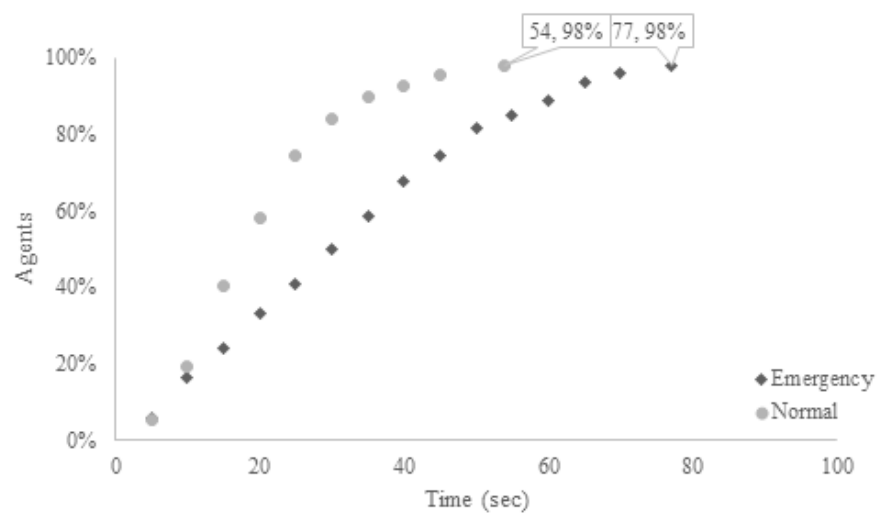

Figure 5: Percentage evacuated over time $(0.45 \mathrm{p} / \mathrm{m} 2)$

The second part of this study evaluates the impact of blocking certain exits on the crowd evacuation. For the second case study where crowd density was equal to $0.45 \mathrm{p} /$ $\mathrm{m} 2$, blocking the east corridor and part of the north corridors resulted in a significantly higher crowd flow towards the south exit, increasing crowd density to almost $6 \mathrm{p} / \mathrm{m} 2$ at the junction where crowds from four directions meet. 

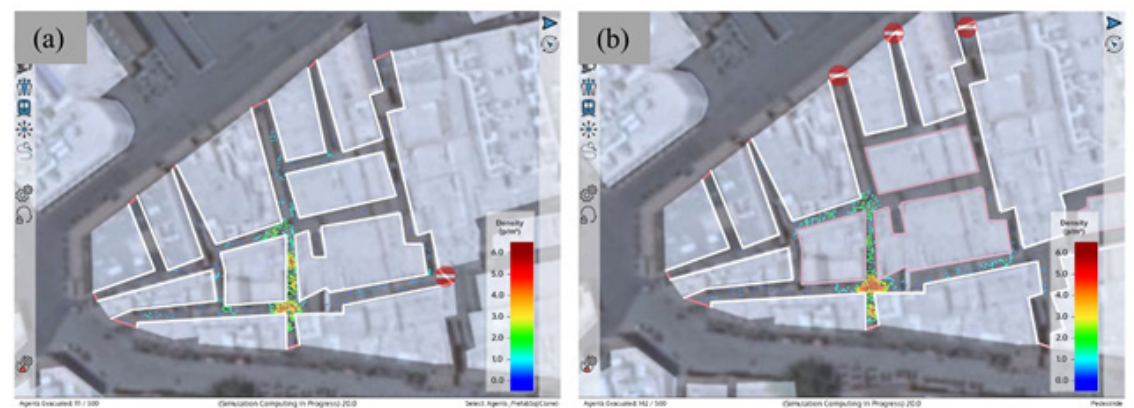

Figure 6: Emergency evacuation at 20 seconds: (a) blocked east corridor, (b) blocked north corridors

Crowd behaviour during evacuation also plays a critical role. Fig. 7 shows the difference between normal and emergency evacuation when east corridor is blocked. In this case, much less congestion is observed at the south exit and crowd could be safely evacuated.
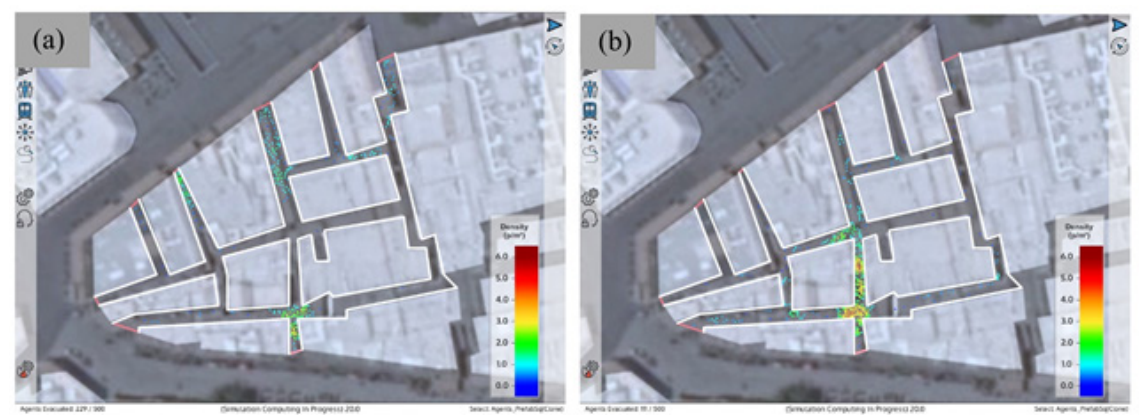

Figure 7: (a) Emergency evacuation and (b) normal evacuation at 20 seconds

Current static exit signs direct the crowd to certain exits as shown in Figure. 8. However, using dynamic signs could mitigate the phenomena observed in Figure. 6. Knowing that crowds may behave in different ways depending on the circumstances of evacuation, these dynamic signs can disseminate variable route guidance information using on-time data on pedestrian density at the different corridors and the clearance of exits which can be collected through the surveillance system. This allows an efficient and safe dynamic crowd management or crowd evacuation process.
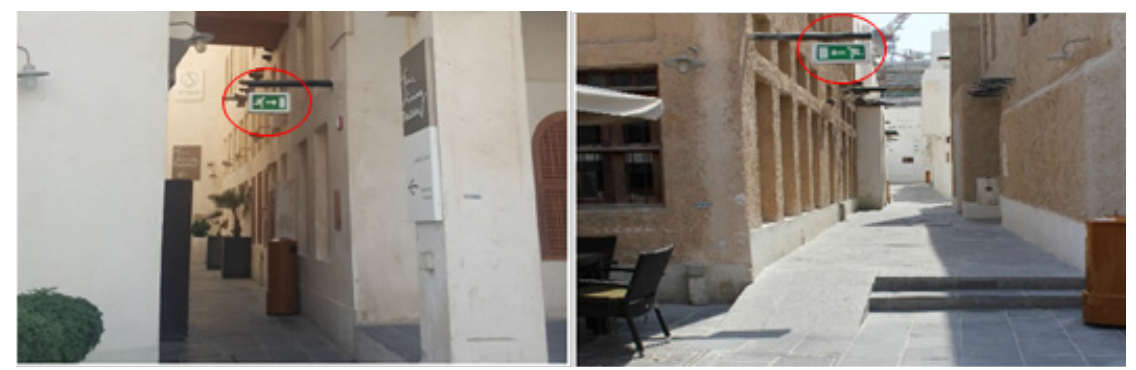

Figure 8: Sample exit signs in Souq Waqif (Furlan and Faggion, 2015) 


\section{CONCLUSION}

Souq Waqif is one of the main tourist attractions that is expected to witness an increasing visitor demand during mega events such as FIFA World Cup 2022. The place is characterized by its maze-like layout with multiple entrances and exits, and quite complex and irregular network of paths that visitors can take. Traders on each side of the corridors display their goods, and some restaurants and cafes have an outdoor dining area. All of these factors reduce the effective width of the passageways and adds to the complexity of navigating through the Souq. The study showed that during normal evacuation, crowds can safely exit the Souq even when certain routes are blocked due to the availability of many exit routes. However, during emergency evacuation and due to herding effect, crowds tend to take the same route what leads to stamping and increased crowd density. In order to avoid such unfavourable situations, dynamic exit signage should be implemented to direct the crowds to clear exit routes.

It should be noted that this an initial study and the results obtained give an overview of the issue and suggest primary solutions to it. The collection of Souq Waqif layout and visitor demands was not possible at this stage. However, required data will be collected in the future with the assistance of relevant authorities. In future, we aim to obtain more accurate drawings of the Souq with accurate path dimensions. Moreover, we intend to calibrate and validate the base models, i.e., the force-based behaviour model and the exit choice model, used in Pedestride ${ }^{\circledR}$ software to represent conditions specific to Qatar.

\section{REFERENCES}

Antonini, G., Bierlaire, M. \& Weber, M. (2006). Discrete choice models of pedestrian walking behavior. Transportation Research Part B: Methodological, 40: 667-687.

Asano, M., Iryo, T. \& Kuwahara, M. (2010). Microscopic pedestrian simulation model combined with a tactical model for route choice behaviour. Transportation Research Part C: Emerging Technologies, 18: 842-855.

Augustijn-Beckers, E.-W., Flacke, J. \& Retsios, B. (2010). Investigating the effect of different pre-evacuation behavior and exit choice strategies using agent-based modeling. Procedia Engineering, 3: 23-35.

Bode, N. W. F. \& Codling, E. A. (2013). Human exit route choice in virtual crowd evacuations. Animal Behaviour, 86: 347-358.

El-Hamalawy, H. (2015). Souq Waqif. Available at: https://www.flickr.com/photos/elhamalawy/23733881160.

Furlan, R. \& Faggion, L. (2015). The Souq Waqif Heritage Site in Doha: Spatial Form and Livability. American Journal of Environmental Engineering, 5: 146-160.

Haghani, M. \& Sarvi, M. (2016). Human exit choice in crowded built environments: Investigating underlying behavioural differences between normal egress and emergency evacuations. Fire Safety Journal 85: 1-9.

Haghani, M. \& Sarvi, M. (2016). Pedestrian crowd tactical-level decision making during emergency evacuations, Journal of Advanced Transportation. 50: 1870-1895.

Haghani, M. \& Sarvi, M. (2018). Crowd behaviour and motion: Empirical methods. Transportation Research Part B: Methodological, 107: 253-294.

Haghani, M., Sarvi, M. \& Shahhoseini, Z. (2015). Accommodating taste heterogeneity and de- 
sired substitution pattern in exit choices of pedestrian crowd evacuees using a mixed nested logit model. Journal of Choice Modelling, 16: 58-68.

Haghani, M., Sarvi, M. \& Rajabifard, A. (2018). Simulating Indoor evacuation of pedestrians: The sensitivity of predictions to directional-choice calibration parameters. Transportation Research Record, 2672: 171-182.

Helbing, D., Farkas, I. \& Vicsek, T. (2000). Simulating dynamical features of escape panic. $\mathrm{Na}$ ture, 407: 487-490.

Kusuma, P. D. (2017). Crowd simulation in souvenir market by using multi agent system. International Journal of Applied Engineering Research, 12: 15055-15065.

Kusuma, P. D., SN, A. \& Pulungan R. (2016a). Agent-based buyer-trader interaction model of traditional markets. International Journal of Intelligent Systems and Applications, 8: 1-8.

Kusuma, P. D., SN, A. \& Pulungan, R. (2016b). Agent-based crowd simulation of daily goods traditional markets. International Journal of Intelligent Systems and Applications, 8: 1-10.

Lovreglio, R., Ronchi, E. \& Nilsson, D. (2015). A model of the decision-making process during pre-evacuation. Fire Safety Journal, 78: 168-179.

Nafi, S. I., Alattar, D. A. \& Furlan, R. (2015). Built form of the Souq Waqif in Doha and user's social engagement. American Journal of Sociological Research, 5: 73-88.

Tannous, H. O. \& Furlan, R. (2018). Livability and urban quality of the Souq Waqif in Doha (State of Qatar). Saudi Journal of Engineering and Technology, 3: 368-387. 